\title{
El sentido de vida, una condición existencial ${ }^{1}$
}

\section{The meaning of life, an existential condition}

Paula Andrea Vanegas Rivas*, Juan Sebastián Marín Rodríguez

Recibido: 17 de abril de 2021 / Aceptado: 4 de junio de 2021 / Publicado: 13 de diciembre de 2021

Forma de citar este artículo en APA:

Vanegas Rivas, P. A., \& Marín Rodríguez, J. S. (2021). El sentido de vida, una condición existencial. Poiésis, (41), 149-155. https://doi.org/10.21501/16920945.4186

\section{Resumen}

El ser humano siempre ha estado en la constante búsqueda de sentido y preguntándose por su existencia. El hombre moderno además de encontrase en esa búsqueda, también se halla permeado por la angustia constante, está sometido a la cosificación de sí mismo, la hiper-conectividad, el consumismo, la incertidumbre y la inmediatez, lo cual lo conduce de manera casi inminente al aburrimiento y el tedio, es decir, a la frustración existencial, llevándolo a enfrentarse con sus pseudo-satisfactores y dejándolo de cara ante el vacío de su propia existencia y el cuestionamiento: ¿para qué estoy en el mundo?

\section{Palabras clave:}

Angustia; Consumismo; Existencialismo; Libertad; Responsabilidad; Sentido de vida; Vacío interior.

El presente artículo es derivado de un análisis crítico del proyecto de investigación finalizado "El fatalismo una manifestación de una crisis existencial contemporánea", desarrollado en el curso de trabajo de grado, en la Universidad Católica Luis Amigó.

Estudiante del programa de Psicología de la Universidad Católica Luis Amigó, Medellín-Colombia.

Contacto: paula.vanegasri@amigo.edu.co

Psicólogo, Especialista en Intervenciones Psicosociales y en Psicología Clínica y Salud Mental, Magister en Desarrollo Infantil, Docente de la Facultad de Psicología y Ciencias Sociales. Universidad Católica Luis Amigó. Medellín-Colombia. Contacto: juan.marinju@amigo.edu.co. https://orcid.org/0000-0002-1598-8088. 


\section{Abstract}

Human beings have been in a constant search for meaning and wondering about its existence. The modern man, in addition to finding himself in this search, is also permeated by constant anguish, is subjected to the objectification of himself, hyperconnectivity, consumerism, uncertainty and immediacy, which leads him almost imminently to boredom, which is existential frustration, leading him to face his pseudosatisfiers and leaving him face to face with the emptiness of his own existence and the question: what am I in the world for?

\section{Keywords:}

Anguish; Consumerism; Existentialism; Freedom; Responsibility; Meaning of life; Inner emptiness. 


\section{Introducción}

Los bosquimanos del desierto de Kalahari hablan de dos hambres. Existe el "Hambre Grande" y el "Hambre Pequeña". El Hambre Pequeña está ligada con la satisfacción de la necesidad de alimentación, es decir, es completamente fisiológica. El Hambre Grande, considerada la más importante de todas, se refiere al hambre de significado, es decir, que toda acción que se realice tenga un significado para la existencia, más allá de la felicidad o la tristeza, el significado es lo que transforma todo (Chang-Dong, 2018).

El ser humano, a lo largo de su vida llega a cuestionarse cuál es el sentido o el significado de su existencia. En la contemplación y exploración del hombre, la filosofía existencial desde sus inicios asignó la existencia únicamente a las personas y no a las cosas, considerándola como una forma de ser propia del hombre (Angarita, 2004), siendo este último el único que puede plantearse preguntas como: ¿para qué estoy en el mundo?, ¿cuál es el sentido de mi vida o existencia? ¿para qué debería vivir o por qué?, ¿qué me motiva?, ¿qué espero de la vida?, ¿qué va a pasar cuando muera?, entre otras. Estos cuestionamientos y la conciencia plena de la vida y la muerte son los que hacen que la comprensión de la existencia y la exploración profunda del ser entren en conflicto 0 en crisis, no basta con preguntarse por la muerte sino también por la vida (Yalom, 1984), ya que las respuestas implican una relación directa entre sí y los demás factores como la condena a la libertad y por ende a la responsabilidad de sus elecciones, el vacío, la frustración existencial y el sentido de vida.

Tal como lo nombra Sartre (2009): "la vida no tiene sentido, a priori. Antes de que ustedes vivan la vida no es nada; les corresponde a ustedes darle un sentido, y el valor no es otra cosa que ese sentido que ustedes eligen" (p. 82). Cuando el hombre revisa su existencia cuestionando el sentido de vida, buscando encontrar significados propios en un mundo sin sentido, choca de manera inmediata con la frustración existencial; respecto a esto, Sánchez (2005) menciona:

El individuo frustrado existencialmente, se queja con frecuencia de su vida sin sentido, experimentando una sensación de vacío interior, e intentando llenar este vacío a través de satisfactores emocionantes como la búsqueda de sensaciones materiales, posesión de dinero y en muchos casos, adicciones, lo cual paradójicamente genera más angustia. (p. 58)

Es posible identificar aspectos clave en la pregunta por el sentido o significado de la existencia, la libertad, la responsabilidad y la frustración existencial, los cuales pueden conducir a otros cuestionamientos cómo: ipor qué el sentido de vida lleva al hombre a sumirse en una angustia 
y frustración existencial?, el ser humano en su plena capacidad de libertad de elección, ¿elige su significado de vida?, ¿por qué es importante la responsabilidad a la hora de plantearse el sentido de vida? y sobre todo, ¿cómo elijo vivir?.

El existencialismo, como movimiento filosófico es el pionero en definir al hombre como el único responsable de su existencia y ser en el mundo, teniendo como premisa, "la existencia precede a la esencia" (Sartre, 2009, p. 30), lo que significa que el hombre comienza existiendo, se encuentra, surge en el mundo y finalmente puede definirse (Sartre, 2009). De esta manera, el existencialismo le otorga al hombre toda la responsabilidad de lo que es, dotándolo de capacidad de elección y sentido de libertad, por tanto, para esta corriente filosófica el hombre no solo puede elegir, sino que tiene que elegir, incluso la no elección también puede considerarse como elegir; en palabras de Sartre (como se cita en Quitmann, 1989, p. 64) el hombre está "condenado a la libertad".

Al referirse a la palabra 'condenado' lo hace aludiendo al tiempo pasado, indicando que hay ciertos aspectos de la vida que no pueden elegirse (Ramírez Giraldo, 2020), es decir, el hombre no puede elegir donde nacer, no elige a cuál clase social pertenecer, ni las enfermedades congénitas que pueda padecer e incluso no elige nacer, hay factores que son imposibles de elegir, y es ahí donde radica la condena, la forma como cuestiona al hombre y este logra darle un significado diferente, que en palabras de Sartre (2009) la condena es el primer paso para ser libre. En el tiempo presente, el ser humano sí puede elegir, tiene la libertad de cambiar una relación que ya no le "haga feliz", dejar un trabajo que no le satisface, puede elegir quién ser y qué hacer con las situaciones que se le presenten (Quitmann, 1989).

La angustia que puede provocar la pregunta por la existencia, es precisamente generada por las elecciones o no elecciones y por la carencia de un propósito o significado para su propia existencia, en palabras de Chillón (2018) "la angustia es el modo de ser del ente que es el Dasein en cuanto deslocalizado, no por no tener un lugar sino porque su lugar sea la nada" (p. 226). En la actualidad, el ser humano sufre bajo un sentimiento de tener menos que otros, se percibe a sí mismo derrotado y extenuado en el ritmo acelerado de la vida actual, observando que en el verdadero trasfondo de la condena del fatalismo (Frankl, 2011), se encuentra la acumulación excesiva, el aislamiento existencial o la inmediatez, el fatalismo, el fanatismo, entre otros, aclarando que la condición de la existencia no radica en el valor de tener, sino en el sentimiento angustioso de una existencia sin sentido, su "destino" se muestra inamovible, inmutable e irreversible, como si estuviera predeterminado desde el principio de su existencia; en palabras de Carmona Aránzazu (2020), en su inmediatez, el hombre no se percata de que él es el dueño y responsable de su destino y que tiene la capacidad innata para modificarlo.

Es posible identificar cómo el hombre moderno, buscando responder a su pregunta por la existencia, contando con su capacidad de elección, elige ser sometido a sistemas que inhiben su condición de libertad; las condiciones donde se encuentra inmerso, no brindan una base para que el hombre ejerza su libertad, lo que hace que esta se convierta en una carga insoportable para el humano, lo lleve a vivir una vida sin sentido y se someta a la angustia; así es como él mismo 
abandona su libertad y busca refugio en la sumisión, en actividades, sistemas, masoquismo, colectivos o cualquier tipo de relación con el mundo que le prometa aliviar su incertidumbre, aun cuando esto le anule su propia libertad (Fromm, 1985).

La palabra responsabilidad en términos coloquiales se asocia con el tener que cumplir algún deber u obligación o hacerse cargo de algo o de alguien; pero en el campo de la salud mental, la responsabilidad es conocida como la capacidad que tienen las personas para estabilizar su conducta de manera racional (Yalom,1984). En el ámbito existencial el término de responsabilidad está ligado a la conciencia, tal como lo indica Yalom (1984): "la responsabilidad implica ser el autor de algo. Y ser consciente de ella es darse cuenta de que uno está creando su propio destino, el propio ser, su predicamento vital, sus sentimientos, y en algunos casos, el propio sufrimiento" (p. 266).

Ante el cuestionamiento existencial, la logoterapia, considera que el hombre no es quién le plantea las preguntas a la vida, sino que es la vida misma quien lo cuestiona y es allí, donde la responsabilidad se vuelve un factor determinante para el sentido de vida, en tanto que, "la logoterapia considera que la esencia de la existencia consiste en la capacidad del ser humano para responder responsablemente a las demandas que la vida le plantea en cada situación particular" (Frankl, 2015, p. 137). Es por ello, que el hombre debe identificar de qué es responsable, y elegir ante qué o quién se hará responsable, si lo hará ante sí mismo y la elección de otorgar de manera responsable su sentido o significado de vida.

La falta de un sentido o de un significado para la vida es lo que provoca angustia, vacío existencial o el "Hambre Grande"; esa falta de objetivo y finalidad es lo que se define como frustración existencial, es decir, el no cumplimiento del deseo de sentido que está impregnado en todas las personas. La ausencia de objetivo y esperanza se refleja en el aburrimiento y el fracaso del deseo humano de encontrar un sentido de vida auténtico (Frankl, 2011). Por tanto, Frankl ofrece una mirada amplia al sentido de vida, indicando que este no es único para todas las personas y que el hombre no puede comparar su destino con el de otros, porque todo varía de uno a otro. Es por ello que, el sentido de vida necesita invariablemente de la voluntad de sentido, la cual es contemplada como la capacidad innata o motivación básica de todos los seres humanos para encontrar el sentido de lo que es y lo que puede ser (Frankl, 2015).

El cuestionamiento por la existencia es un hecho inherente al hombre, este siempre se encuentra en la búsqueda de un sentido o un significado por el cual vivir. El ser humano, sumergido en el mundo moderno, se ve influenciado por grandes "satisfactores" impuestos por el consumismo, la competitividad, la cosificación de sí mismo, el materialismo, el fanatismo y hasta el fatalismo, estos a su vez, lo llevan a forjar la creencia de que son los medios adecuados para darle un sentido a su existencia o saciar su "Hambre Grande"; el exceso de trabajo para conseguir el éxito, estar a la vanguardia con las tecnologías, someterse a grupos políticos o religiosos y el aislamiento interpersonal parecen ser la respuesta a la pregunta ¿para qué vivir? No obstante, cuando el hombre se enfrenta a sí mismo frente a la finitud de su existencia, se da cuenta que lo anterior son solo unos pseudo-satisfactores que aumentan su vacío existencial y que no responden con claridad a su significado de vida, llevándolo a experimentar una profunda frustración existencial. 
Se podría comparar el sentido de vida con una maleta, la cual es asignada a cada hombre cuando es arrojado al mundo, para llevarla a lo largo de su existencia; el contenido de dicha maleta es la voluntad de sentido, se ocupa con lo que se cree que es necesario para darle un significado a la vida; cuando la maleta se desocupa por algún motivo, es cuando el hombre experimenta el vacío existencial, es decir, no encuentra cual es el sentido, pero, cuando la maleta es colmada de cosas que no se necesitan, que no satisfacen el "Hambre Grande", a esto se le llama frustración existencial. Esta comparación, permite dilucidar que la responsabilidad le pertenece a cada hombre, el mantener su maleta, cargarla, llenarla y vaciarla cuantas veces considere necesario, ninguna maleta es igual a otra. El cuidado y el significado de esta se los otorga su dueño. Así mismo, el hombre es quien elige bajo su capacidad de elección o libertad, los factores o acciones que le darán un significado a su existencia.

Desde el comienzo de su existencia el hombre se ve obligado a elegir entre diversos cursos de acción. En el animal hay una cadena ininterrumpida de acciones que se inicia con un estímulo -como el hambre- y termina con un tipo de conducta más o menos estrictamente determinado, que elimina la tensión creada por el estímulo. En el hombre esa cadena se interrumpe. El estímulo existe, pero la forma de satisfacerlo permanece "abierta", es decir, debe elegir entre diferentes cursos de acción. En lugar de una acción instintiva predeterminada, el hombre debe valorar mentalmente diversos tipos de conducta posibles; empieza a pensar. (...) Va adquiriendo una oscura conciencia de sí mismo (...) Llega a ser consciente de la muerte en tanto que destino final, aun cuando trate de negarla a través de múltiples fantasías (Fromm, 1985, pp. 55-56).

\section{Conflicto de intereses}

Los autores declaran la inexistencia de conflicto de interés con institución o asociación comercial de cualquier índole.

\section{Referencias}

Angarita, J. M. (2004). Conductismo skinneriano y existencialismo sartreano: encuentros y desencuentros. Suma Psicológica, 11(1), 111-121. http://publicaciones.konradlorenz.edu.co/index. php/sumapsi/article/view/90/72 
Carmona Aránzazu, I. D. (2020). Libertad o destino: el laberinto de la condición humana. Escritos, 23(50), 13-21. https://revistas.upb.edu.co/index.php/escritos/article/view/556

Chang-Dong, L. (Productor y Director). (2018). Burning [Película]. NHK.

Chillón, J. M. (2018). Los rendimientos fenomenológicos de la angustia en Heidegger. Alpha (Osorno), (46), 215-232. https://dx.doi.org/10.4067/S0718-22012018000100215

Frankl, V. (2011). La psicoterapia al alcance de todos: conferencias radiofónicas sobre terapéutica psíquica. Editorial Herder S.A.

Frankl, V. (2015). El hombre en busca de sentido (3. ed.). Editorial Herder.

Fromm, E. (1985). Obras maestras del pensamiento contemporáneo. Editorial Planeta-De Agostini.

Quitmann, H. (1989). Psicología humanística, conceptos fundamentales y trasfondo filosófico. Editorial Herder.

Ramírez Giraldo, C. A. (2020). De la condena a la libertad en Sartre a la esperanza creíble en Kierkegaard. Escritos, 18(40), 186-203. https://revistas.upb.edu.co/index.php/escritos/article/ view/6762/6367

Sánchez, J. (2005). El fatalismo como forma de ser en el mundo del latinoamericano. Psicogente, 8(13), 55-65. http://revistas.unisimon.edu.co/index.php/psicogente/article/view/1550

Sartre, J. P. (2009). El existencialismo es un humanismo. Edhasa.

Yalom, I. (1984). Psicoterapia existencial. Editorial Herder. 